Article

\title{
Elemental Mercury Adsorption by Cupric Chloride-Modified Mesoporous Carbon Aerogel
}

\author{
Dongjing Liu ${ }^{1}$, Cheng $\mathrm{Lu}^{2}$ and Jiang $\mathrm{Wu}^{2, *}$ \\ 1 School of Energy and Power Engineering, Jiangsu University, Zhenjiang 212013, China; \\ liudongjing19@163.com \\ 2 College of Energy and Mechanical Engineering, Shanghai University of Electric Power, \\ Shanghai 200090, China; luchengsuep@163.com \\ * Correspondence: wujiang207@163.com or wujiang@shiep.edu.cn; Tel./Fax: +86-02135303902
}

Received: 28 October 2018; Accepted: 30 November 2018; Published: 2 December 2018

\begin{abstract}
Mesoporous carbon aerogels (MCA) synthesized via aqueous polymerization of resorcinol and formaldehyde were modified by copper chloride and applied for adsorption removal of elemental mercury $\left(\mathrm{Hg}^{0}\right)$ at a low temperature. The sorbents were characterized by field emission scanning electron microscopy (FESEM), X-ray diffraction (XRD), nitrogen adsorption/desorption isotherms, and X-ray photoelectron spectroscopy (XPS) techniques. The results show that $\mathrm{CuCl}_{2}$-modified $\mathrm{MCA}$ exhibited good ability for $\mathrm{Hg}^{0}$ adsorption in the $40-160{ }^{\circ} \mathrm{C}$ temperature range, with $\mathrm{Hg}^{0}$ removal efficiency all above $95.0 \%$. The $\mathrm{Hg}^{0}$ removal efficiency first increased and then decreased with the elevation of reaction temperature. It performed optimally at $80{ }^{\circ} \mathrm{C}$ with the highest $\mathrm{Hg}^{0}$ removal efficiency of $98.7 \%$. XPS results indicate that covalent chlorines (C-Cl groups) play an important role in elemental mercury adsorption process. $\mathrm{Hg}^{0}$ is firstly captured in the form of oxidized mercury $\left(\mathrm{Hg}^{2+}\right)$ and then reacts with $\mathrm{C}-\mathrm{Cl}$ groups to form $\mathrm{HgCl}_{2}$.
\end{abstract}

Keywords: elemental mercury; carbon aerogel; covalent chlorine; copper chloride

\section{Introduction}

Mercury is one of the most toxic heavy metal elements in the environment due to its high volatility, long persistence, and strong bioaccumulation property [1]. Coal-fired power plants are the dominant anthropogenic mercury emission sources [2]. Elemental mercury, oxidized mercury, and particle-bound mercury are three types of mercury species in flue gas [3]. On account of its low aqueous insolubility and high vaporability, elemental mercury $\left(\mathrm{Hg}^{0}\right)$ capture from flue gas is considered the hardest and most urgent work in the mercury emission control of coal-fired power plants [4].

Adsorption removal of elemental mercury by using solid sorbents is a viable method with respect to mercury emission control of coal-fired power plants [5]. Enormous carbon-based or noncarbon-based materials, e.g., biomass-derived chars [6], activated carbon [7], fly ash [8], as well as natural minerals [9], had been extensively studied for elemental mercury removal from flue gas. However, most of them exhibit limited mercury adsorption capacity and poorer $\mathrm{Hg}^{0}$ removal efficiency at low temperatures under flue gas free of $\mathrm{HCl}$ [10]. Carbon aerogels consisting of interconnected and uniform particles with well-defined pore architectures are promising sorbents for elemental mercury capture [11]. The large surface area and high porosity of carbon aerogels could offer abundant active sites for $\mathrm{Hg}^{0}$ adsorption and benefits a mass transfer process (e.g., $\mathrm{Hg}^{0}$ vapor diffusion) [12]. $\mathrm{CuCl}_{2}$-modification is found to be effective for mercury adsorption, and the chlorine ions contained in $\mathrm{CuCl}_{2}$ are favorable for $\mathrm{Hg}^{0}$ oxidation in chlorine-free flue gas [13]. In addition, $\mathrm{CuCl}_{2}$ possesses the advantage of lower capital cost compared with the commonly used metal oxide additives. Yang et al. [14] developed a $\mathrm{CuCl}_{2}$-modified magnetosphere for elemental mercury removal. It performed optimally at $150{ }^{\circ} \mathrm{C}$ with the highest $\mathrm{Hg}^{0}$ 
removal efficiency of $90.6 \%$. Zhou et al. [15] synthesized a $\mathrm{CuCl}_{2}$-impregnated $\mathrm{CeO}_{2}-\mathrm{ZrO}_{2}$ sorbent for $\mathrm{Hg}^{0}$ removal in chlorine-free coal combustion flue gas. They revealed that the interaction between $\mathrm{Cl}$ and chemical adsorbed oxygen contributed to its superior and stable mercury capture performance with a $\mathrm{Hg}^{0}$ removal efficiency of $89.6-97.1 \%$. Therefore, $\mathrm{CuCl}_{2}$ is employed as the additive for carbon aerogels for the sake of combining the prominent oxidation ability of $\mathrm{CuCl}_{2}$ and the good mass transfer ability of carbon aerogels toward elemental mercury adsorption.

In this work, mesoporous carbon aerogels (MCA) with large pore volume $\left(>1 \mathrm{~cm}^{3} / \mathrm{g}\right)$ and large specific surface area $\left(>500 \mathrm{~m}^{2} / \mathrm{g}\right)$ were synthesized via the sol-gel method. The as-prepared MCA was subsequently modified with $\mathrm{CuCl}_{2}$ by using the pore volume impregnation approach for $\mathrm{Hg}^{0}$ adsorption at an upflow bench-scale fixed-bed reactor in the temperature range of $40-160{ }^{\circ} \mathrm{C}$. The samples were characterized by using field emission scanning electron microscopy (FESEM), X-ray diffraction (XRD), nitrogen adsorption/desorption, and X-ray photoelectron energy spectroscopy (XPS) techniques. The effects of $\mathrm{CuCl}_{2}$ concentration and reaction temperature on $\mathrm{Hg}^{0}$ adsorption performances of $\mathrm{CuCl}_{2}$-modified MCA were investigated. Furthermore, the reaction mechanism of $\mathrm{Hg}^{0}$ capture over $\mathrm{CuCl}_{2}$-modified MCA is also addressed according to the XPS analysis results. $\mathrm{Cu} 06 \mathrm{MCA}, \mathrm{Cu} 18 \mathrm{MCA}$, and Cu30MCA denote the MCA modified by $\mathrm{CuCl}_{2}$ with molar concentrations of $0.06,0.18$, and $0.30 \mathrm{~mol} / \mathrm{L}$, respectively.

\section{Results and Discussions}

\subsection{Characterization Analysis}

The FESEM images of pristine and $\mathrm{CuCl}_{2}$-modified MCA are shown in Figure 1. The as-prepared MCA was formed by interconnected irregular spherical particles (Figure 1a), and many pores were produced among the particles which aggregated together. After modification with cupric chloride, the surface of the MCA became a little bit compact, and the MCA particles cohered together (Figure 1b), probably leading to the reduction of the Brunauer-Emmett-Teller (BET) surface area (Table 1).
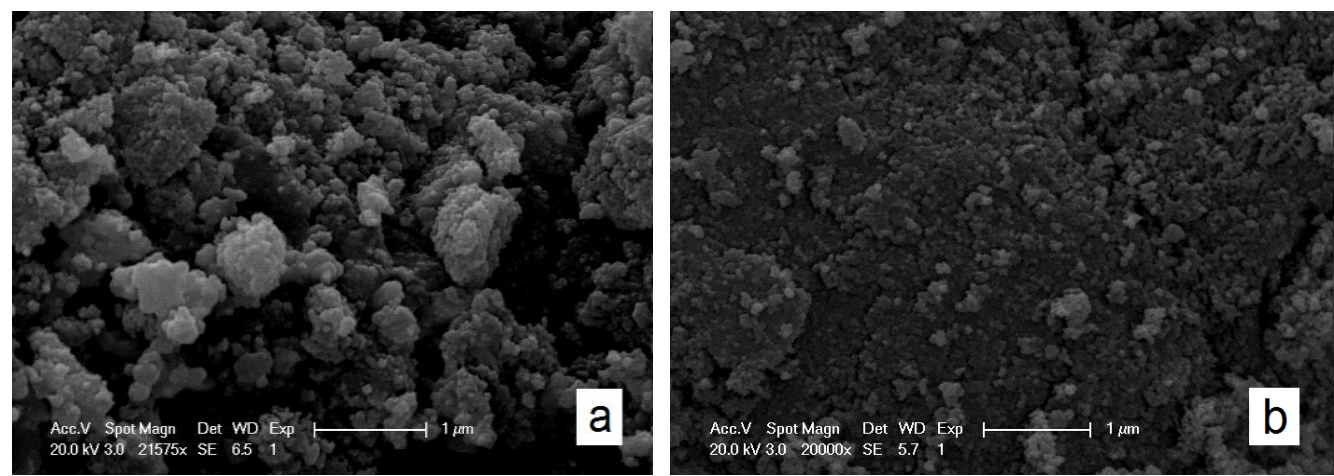

Figure 1. Field emission scanning electron microscopy (FESEM) images: (a) Mesoporous carbon aerogels (MCA) and (b) Cu18MCA.

The XRD patterns of pristine and $\mathrm{CuCl}_{2}$-modified MCA are presented in Figure 2. The bigger broad diffraction peaks at $23.9^{\circ}$ were assigned to the reflection of the (002) lattice plane of activated carbon and graphite. The smaller broad diffraction bands at $\sim 43.6^{\circ}$ were attributed to the reflection of the (100) lattice plane of graphite [16,17]. The signals of $\mathrm{CuCl}_{2}$ were not detected in $\mathrm{CuCl}_{2}$-modified MCA, probably owing to the smaller content of $\mathrm{CuCl}_{2}$ or the thorough dispersion of amorphous $\mathrm{CuCl}_{2}$ on the MCA surface. 


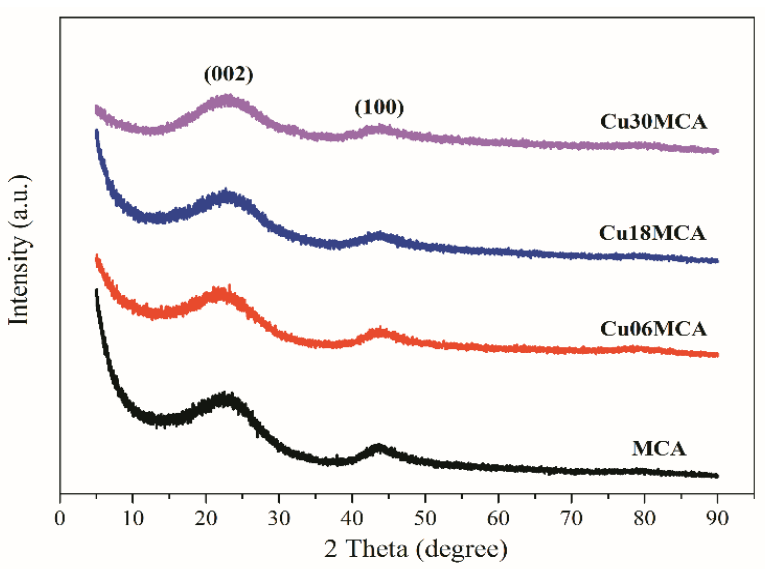

Figure 2. X-ray diffraction (XRD) patterns of pristine and $\mathrm{CuCl}_{2}$-modified $\mathrm{MCA}$.

The nitrogen adsorption-desorption isotherms and pore size distributions of pristine as well as $\mathrm{CuCl}_{2}$-modified MCA are displayed in Figure 3. The MCA exhibited type IV isotherm (Figure 3a). The position of the hysteresis loop at the higher relative pressure of above 0.8 implies the presence of large mesopores on the MCA surface [18], which is consistent with the broad pore size distribution centered between 10 and $30 \mathrm{~nm}$. The BET surface area, total pore volume, and pore diameter of the MCA were $523 \mathrm{~m}^{2} / \mathrm{g}, 1.21 \mathrm{~cm}^{3} / \mathrm{g}$, and $9.2 \mathrm{~nm}$, respectively (Table 1). After modifying with $\mathrm{CuCl}_{2}$, the mesoporous structures of the MCA were still preserved. However, the pore size distribution became narrow, with pore diameter centered at $\sim 16 \mathrm{~nm}$ (Figure 3b).
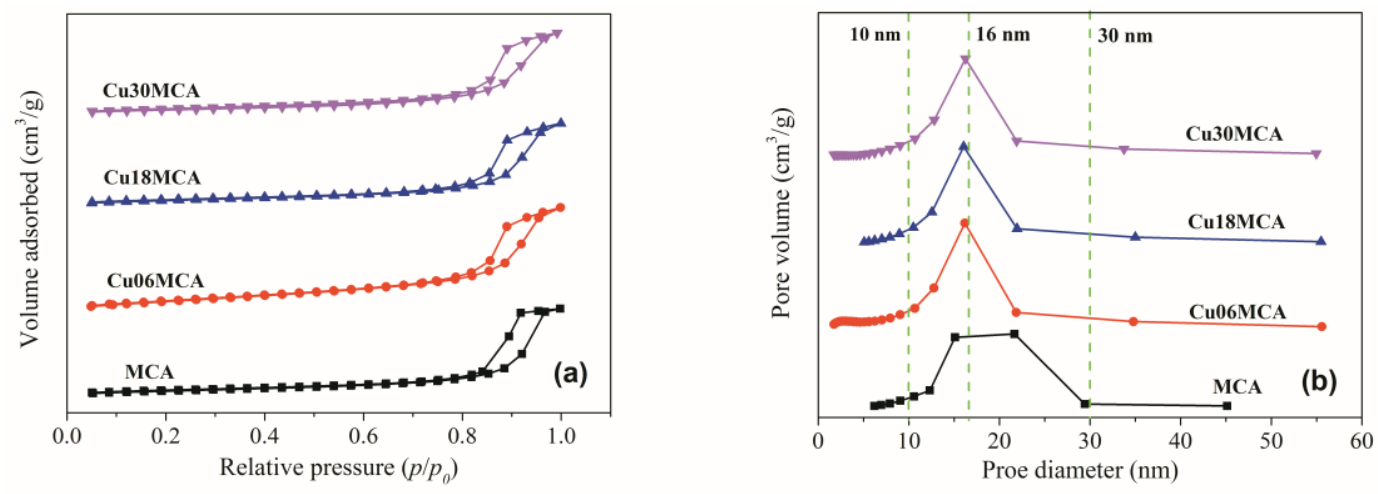

Figure 3. (a) Nitrogen adsorption-desorption isotherms and (b) pore size distributions of pristine and $\mathrm{CuCl}_{2}$-modified MCA.

Table 1. Textural property of pristine and $\mathrm{CuCl}_{2}$-modified MCA.

\begin{tabular}{|c|c|c|c|c|c|}
\hline Samples & $\begin{array}{c}\text { Surface } \\
\text { Area }\left(\mathrm{m}^{2} / \mathrm{g}\right)\end{array}$ & $\begin{array}{c}\text { Total Pore } \\
\text { Volume }\left(\mathrm{cm}^{3} / \mathrm{g}\right)\end{array}$ & $\begin{array}{c}\text { Micropore } \\
\text { Volume }\left(\mathrm{cm}^{3} / \mathrm{g}\right)\end{array}$ & $\begin{array}{c}\text { Mesopore } \\
\text { Volume }\left(\mathrm{cm}^{3} / \mathrm{g}\right)\end{array}$ & $\begin{array}{l}\text { Pore Diameter } \\
(\mathrm{nm})\end{array}$ \\
\hline MCA & 523 & 1.21 & 0.15 & 1.06 & 9.2 \\
\hline Cu06MCA & 641 & 1.38 & 0.06 & 1.32 & 8.6 \\
\hline Cu18MCA & 474 & 1.12 & 0.12 & 1.00 & 9.5 \\
\hline Cu30MCA & 413 & 1.09 & 0.11 & 0.98 & 10.6 \\
\hline
\end{tabular}

The XPS spectra of fresh and spent Cu18MCA are displayed in Figure 4 to determine the surface species on sorbent surfaces. The $\mathrm{C} 1 \mathrm{~s}$ spectra can be deconvoluted into five components in which chemical shifts are assigned to carboxyl groups $(\sim 288.6 \mathrm{eV}), \mathrm{C}=\mathrm{O}$ bonds $(\sim 287.0$ and $\sim 287.2 \mathrm{eV})$, C-OH groups $(\sim 285.4, \sim 285.6$, and $286.2 \mathrm{eV})$, and graphitic carbon $\left(\mathrm{sp}^{2}\right.$ configuration: $\sim 284.2$ and $\sim 284.8 \mathrm{eV}$ ) [18]. In addition, the broad band at $\sim 290.0 \mathrm{eV}$ is related to shake-up satellite peaks assigned to $\pi-\pi^{*}$ transitions in aromatic rings [19]. The $\mathrm{Cu} 2 \mathrm{p}$ peak of fresh Cu18MCA at $\sim 935.8 \mathrm{eV}$ is assigned 
to the reflection of $\mathrm{Cu}^{2+}$ ions in $\mathrm{CuCl}_{2}$ [20]. It shifts slightly toward higher values of $936.2 \mathrm{eV}$ after $\mathrm{Hg}^{0}$ adsorption, possibly attributed to the formation of an oxychloride phase $\mathrm{Cu}_{2} \mathrm{OCl}_{2}$ [21], which is an important intermediate for mercury oxidation. As for spent Cu18MCA, the signal at $105.4 \mathrm{eV}$ is due to the reflection of $\mathrm{Hg} 4 \mathrm{f} 5 / 2$ orbit of oxidized mercury, implying that $\mathrm{Hg}^{0}$ transformed into $\mathrm{Hg}^{2+}$ during the mercury adsorption process [22]. The peaks at $\sim 200.2$ and $\sim 202.4 \mathrm{eV}$ belong to covalent chlorine (C-Cl groups), while the bands at $\sim 198.2$ and $\sim 199.8 \mathrm{eV}$ are ascribed to ionic chlorine ( $\mathrm{Cl}^{-}$ions) [23]. The content of the covalent chlorine (C-Cl groups) decreased from $81.3 \%$ to $47.8 \%$ for fresh and spent $\mathrm{Cu} 18 \mathrm{MCA}$, respectively, indicating that some $\mathrm{C}-\mathrm{Cl}$ groups transformed into $\mathrm{Cl}^{-}$ions during the mercury adsorption process [24]. Since the mercury on the surface of spent Cu18MCA exists in an oxidation state $\left(\mathrm{Hg}^{2+}\right)$, the adsorbed mercury on the sorbent surface may react with $\mathrm{C}-\mathrm{Cl}$ groups to form $\mathrm{HgCl}_{2}$, and therefore the reaction mechanism of elemental mercury reacting with covalent chlorine ( $\mathrm{C}-\mathrm{Cl}$ groups) can be summarized as follows [25]: (i) $\mathrm{Cl}^{-}$ions combined with carbon atoms to form $\mathrm{C}-\mathrm{Cl}$ groups; (ii) gaseous $\mathrm{Hg}^{0}$ was oxidized by $\mathrm{Cu}_{2} \mathrm{OCl}_{2}$ and captured on the sorbent surface in the form of oxidized mercury $\left(\mathrm{Hg}^{2+}\right)$; and (iii) finally, the adsorbed mercury reacted with the $\mathrm{C}-\mathrm{Cl}$ groups to generate $\mathrm{HgCl}_{2}$.
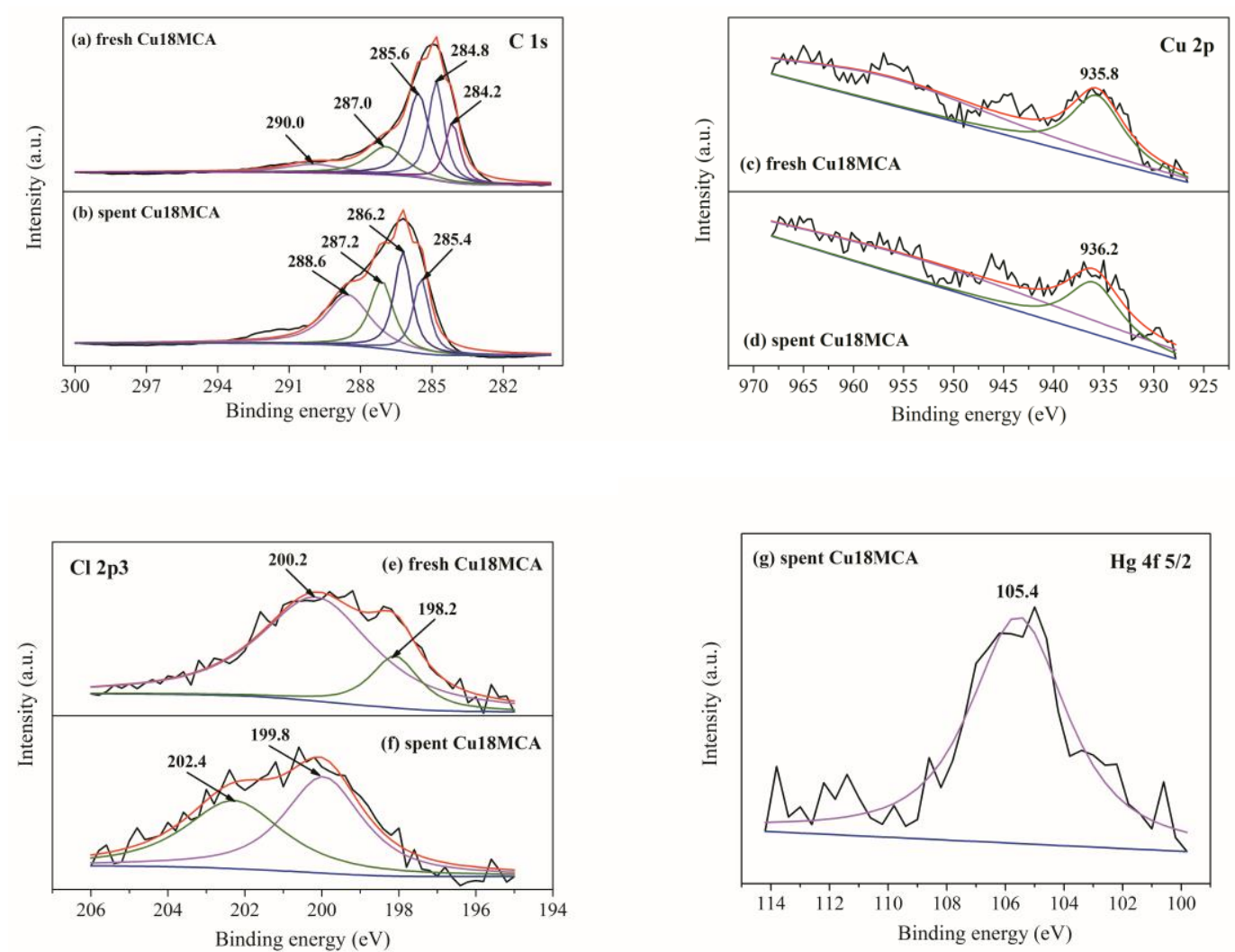

Figure 4. X-ray photoelectron spectroscopy (XPS) spectra of $(\mathbf{a}, \mathbf{c}, \mathbf{e})$ fresh Cu18MCA and $(\mathbf{b}, \mathbf{d}, \mathbf{f}, \mathbf{g})$ spent Cu18MCA.

\subsection{Effect of $\mathrm{CuCl}_{2}$ Concentration}

The impact of $\mathrm{CuCl}_{2}$ concentration on $\mathrm{Hg}^{0}$ adsorption performance at $120{ }^{\circ} \mathrm{C}$ is presented in Figure 5. Pristine MCA showed weaker $\mathrm{Hg}^{0}$ adsorption ability. Though the $\mathrm{Hg}^{0}$ removal efficiency could reach as high as $\sim 88.0 \%$ within $2 \mathrm{~min}$, it dropped rapidly with the time elapsed and maintained at only $\sim 27.3 \%$ after mercury adsorption over $80 \mathrm{~min}$. The probable reason is that $\mathrm{Hg}^{0}$ adsorption on MCA is a physisorption process, and the number of the active sites of MCA will be consumed during mercury adsorption process, leading to the rapid decrease in $\mathrm{Hg}^{0}$ removal efficiency. However, the $\mathrm{Hg}^{0}$ capture ability of MCA can be effectively improved by loading with $\mathrm{CuCl}_{2}$. The $\mathrm{CuCl}_{2}$-modified MCA performed well toward $\mathrm{Hg}^{0}$ adsorption, with $\mathrm{Hg}^{0}$ removal efficiency all above $96.0 \%$ due to the 
addition of new chemisorption sites $\left(\mathrm{Cu}_{2} \mathrm{OCl}_{2}\right.$ and $\mathrm{C}-\mathrm{Cl}$ group) [26]. The $\mathrm{Hg}^{0}$ removal efficiency of MCA significantly rose to $\sim 97.3 \%$ and $\sim 97.6 \%$ when $\mathrm{CuCl}_{2}$ concentrations were $0.06 \mathrm{~mol} / \mathrm{L}$ and $0.18 \mathrm{~mol} / \mathrm{L}$, respectively. However, it dropped slightly to $\sim 96.3 \%$ when $\mathrm{CuCl}_{2}$ concentration further increased from 0.18 to $0.30 \mathrm{~mol} / \mathrm{L}$. According to the nitrogen adsorption-desorption data, when $\mathrm{CuCl}_{2}$ concentration was $0.30 \mathrm{~mol} / \mathrm{L}$, BET surface area and pore volume greatly decreased thereby weakening the mercury adsorption process because excessive $\mathrm{CuCl}_{2}$ will deteriorate the pore structures of the MCA. Thus, the optimal $\mathrm{CuCl}_{2}$ concentration is $0.18 \mathrm{~mol} / \mathrm{L}$.

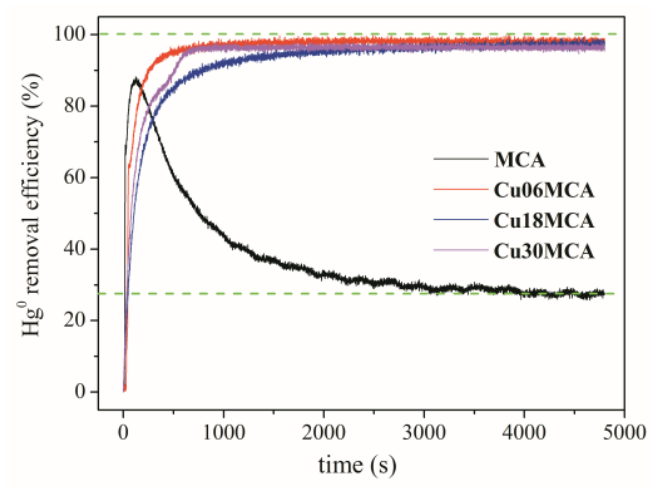

Figure 5. Effect of $\mathrm{CuCl}_{2}$ concentration on $\mathrm{Hg}^{0}$ adsorption performance of $\mathrm{MCA}$ at $120^{\circ} \mathrm{C}$.

\subsection{Effect of Reaction Temperature}

The impact of reaction temperature on $\mathrm{Hg}^{0}$ adsorption performance of $\mathrm{Cu} 18 \mathrm{MCA}$ is presented in Figure 6. Cu18MCA performed well toward $\mathrm{Hg}^{0}$ adsorption in the $40-160{ }^{\circ} \mathrm{C}$ temperature range, with $\mathrm{Hg}^{0}$ removal efficiency all above $95.0 \%$, indicating that $\mathrm{Hg}^{0}$ adsorption on $\mathrm{CuCl}_{2}$-modifed $\mathrm{MCA}$

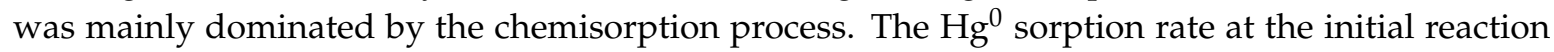
stage and the equilibrium of $\mathrm{Hg}^{0}$ removal efficiency first increased and then decreased with the reaction temperature rising from 40 to $160^{\circ} \mathrm{C}$. Cu18MCA performed the best at $80{ }^{\circ} \mathrm{C}$ with the fastest $\mathrm{Hg}^{0}$ sorption rate and the highest $\mathrm{Hg}^{0}$ removal efficiency of $\sim 98.7 \%$. Though higher temperatures can enhance chemisorption processes [27], the product mercury chloride will decompose at elevated temperatures, resulting in the decline of $\mathrm{Hg}^{0}$ removal efficiency. Thus, the optimal reaction temperature for $\mathrm{Cu} 18 \mathrm{MCA}$ is $80^{\circ} \mathrm{C}$. In addition, Cu18MCA performance was fairly stable over $600 \mathrm{~min}$ on stream, with $\mathrm{Hg}^{0}$ removal efficiency staying above $98.0 \%$ all times (Figure 7).

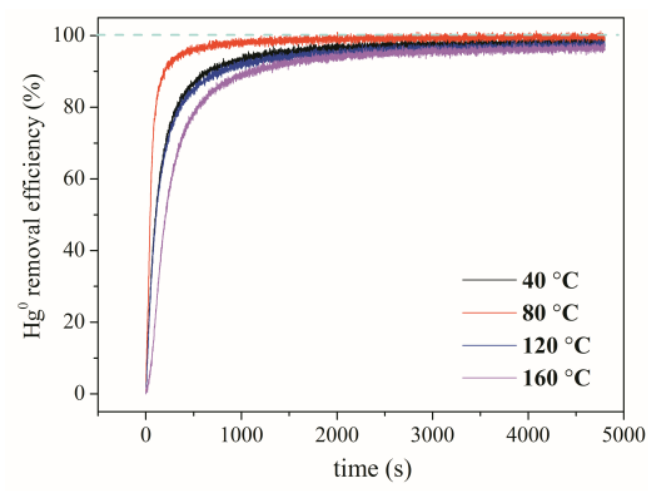

Figure 6. Effect of reaction temperature on $\mathrm{Hg}^{0}$ adsorption performance of Cu18MCA. 


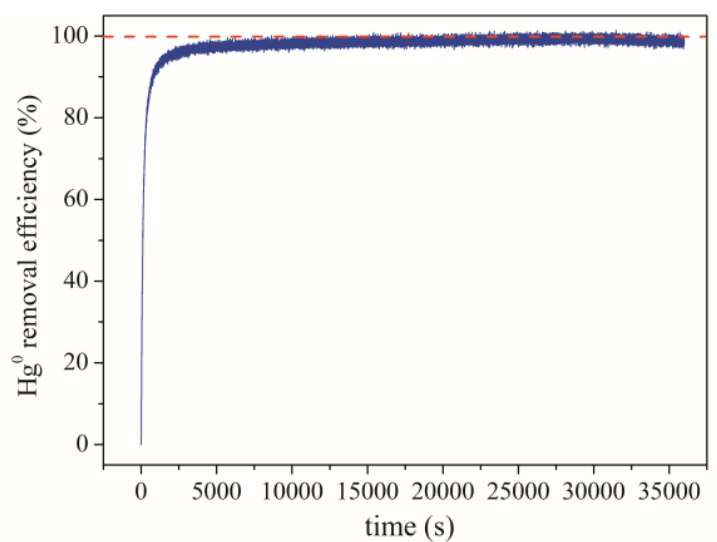

Figure 7. $\mathrm{Hg}^{0}$ adsorption performance of $\mathrm{Cu} 18 \mathrm{MCA}$ at $120^{\circ} \mathrm{C}$ on stream over $600 \mathrm{~min}$.

\section{Experimental}

\subsection{Catalyst Synthesis and Characterization}

Mesoporous carbon aerogels (MCA) were synthesized via the aqueous polymerization of resorcinol and formaldehyde [28]. $\mathrm{CuCl}_{2}$-modified $\mathrm{MCA}$ was fabricated via the incipient wetness impregnation method. First, certain amounts of $\mathrm{CuCl}_{2} \cdot 2 \mathrm{H}_{2} \mathrm{O}$ were dissolved in $3.0 \mathrm{~g}$ of deionized water to obtain solutions with $\mathrm{CuCl}_{2}$ molar concentrations of $0.06,0.18$, and $0.30 \mathrm{~mol} / \mathrm{L}$, respectively. Then, about $1.0 \mathrm{~g}$ of as-prepared MCA was added into the aforementioned solution and subsequently dried at $70{ }^{\circ} \mathrm{C}$ overnight. The resultant sorbents were denoted as Cu06MCA, Cu18MCA, and Cu30MCA, respectively. The FESEM images were detected on a Phillips XL-30 FEG/NEW instrument (Eindhoven, The Netherlands). The XRD patterns were measured on Bruker D8 Advance equipment (Karlsruhe, Germany). The nitrogen isotherms were examined at $77 \mathrm{~K}$ on a Beishide 3H-2000PS4 apparatus (Norcross, GA, USA). The pore size distributions were estimated with the Barrett-Joyner-Halenda $(\mathrm{BJH})$ method using the desorption branch of $\mathrm{N}_{2}$ isotherm, which is expressed by the Kelvin equation as follows:

$$
\ln \left(p^{*} / p_{0}\right)=-\left(\frac{2 \gamma v \cos \theta}{R \operatorname{Tr}_{m}}\right)
$$

where $p^{*}$ is the condensing pressure, $p_{0}$ is the saturated vapor pressure, $\gamma$ is the liquid surface tension, $v$ is the adsorbate molar volume, $\theta$ is the angle between the liquid and solid surface, and $r_{\mathrm{m}}$ is the mean radius of curvature of the liquid meniscus. XPS analyses were carried out on a RBD upgraded PHI-5000C ESCA system (Perkin Elmer, Waltham, MA, USA) with Mg K $\alpha$ radiation $(h v=1253.6 \mathrm{eV})$ or $\mathrm{Al} \mathrm{K} \alpha$ radiation $(h v=1486.6 \mathrm{eV})$.

\subsection{Mercury Adsorption}

The mercury adsorption testing system has been described in detail elsewhere [29,30]. About $50 \mathrm{mg}$ of sorbents were loaded into a fixed-bed reactor and heated up to the desired temperatures. Then, the nitrogen stream containing $\mathrm{Hg}^{0}$ vapor produced by a mercury generator at $50{ }^{\circ} \mathrm{C}$ was consecutively charged into the reactor. $\mathrm{Hg}^{0}$ concentration was measured by an on-line mercury analyzer (Lumex, RA-915-M, St. Petersburg, Russia). The mercury conversion can be attained by

$$
\eta=\left(1-C_{\text {out }} / C_{\text {in }}\right) \times 100 \%
$$

where $\eta$ denotes the mercury removal efficiency (\%), and $C_{i n}$ and $C_{\text {out }}$ denote the inlet and outlet mercury concentration $\left(\mu \mathrm{g} / \mathrm{m}^{3}\right)$, respectively. 


\section{Conclusions}

$\mathrm{CuCl}_{2}$-modified MCA exhibited excellent $\mathrm{Hg}^{0}$ adsorption performance in the temperature range of $40-160{ }^{\circ} \mathrm{C}$. The $\mathrm{Hg}^{0}$ removal performance of $\mathrm{Cu} 18 \mathrm{MCA}$ first ascended and then descended with rising reaction temperatures. It possessed the highest $\mathrm{Hg}^{0}$ removal efficiency of $\sim 98.7 \%$ and the fastest $\mathrm{Hg}^{0}$ sorption rate at $80{ }^{\circ} \mathrm{C}$. Chemisorption dominated the mercury adsorption process over $\mathrm{CuCl}_{2}$-modified MCA. Covalent chlorine ( $\mathrm{C}-\mathrm{Cl}$ groups) played a crucial role in elemental mercury adsorption process. $\mathrm{Hg}^{0}$ was first oxidized by $\mathrm{Cu}_{2} \mathrm{OCl}_{2}$ and captured in the form of oxidized mercury $\left(\mathrm{Hg}^{2+}\right)$ and then reacted with $\mathrm{C}-\mathrm{Cl}$ groups to form $\mathrm{HgCl}_{2}$.

Author Contributions: D.L. designed the experiments, analyzed the data, and wrote the paper. C.L. performed the experiments and characterized the samples. J.W. conceived the project.

Funding: This research was supported by the Fund for Senior Personnel of Jiangsu University (18JDG017) and the National Natural Science Foundation of China (21237003).

Conflicts of Interest: The authors declare no conflict of interest.

\section{References}

1. Krabbenhoft, D.P.; Sunderland, E.M. Global change and mercury. Science 2013, 341, 1457-1458. [CrossRef] [PubMed]

2. Reddy, B.M.; Durgasri, N.; Kumar, T.V.; Bhargava, S.K. Abatement of gas-phase mercury-recent developments. Catal. Rev. Sci. Eng. 2012, 54, 344-398. [CrossRef]

3. Galbreath, K.C.; Zygarlicke, C.J. Mercury speciation in coal combustion and gasification flue gases. Environ. Sci. Technol. 1996, 30, 2421-2427. [CrossRef]

4. Yang, S.; Guo, Y.; Yan, N.; Qu, Z.; Xie, J.; Yang, C.; Jia, J. Capture of gaseous elemental mercury from flue gas using a magnetic and sulfur poisoning resistant sorbent $\mathrm{Mn} / \gamma-\mathrm{Fe}_{2} \mathrm{O}_{3}$ at lower temperatures. J. Hazard. Mater. 2011, 186, 508-515. [CrossRef] [PubMed]

5. Vidic, R.D.; Siler, D.P. Vapor-phase elemental mercury adsorption by activated carbon impregnated with chloride and chelating agents. Carbon 2001, 39, 3-14. [CrossRef]

6. Yang, W.; Xu, W.; Liu, Z.; Liu, Y. Removal of elemental mercury from simulated flue gas using sargassum chars modified by $\mathrm{NH}_{4} \mathrm{Br}$ reagent. Fuel 2018, 214, 196-206. [CrossRef]

7. Padak, B.; Wilcox, J. Understanding mercury binding on activated carbon. Carbon 2009, 47, $2855-2864$. [CrossRef]

8. Xun, G.; Yao, H.; Zhang, D.; Qiao, Y.; Li, L.; Xu, M. Leaching characteristics of heavy metals in fly ash from a Chinese coal-fired power plant. Asia-Pacific J. Chem. Eng. 2010, 5, 330-336.

9. Ding, F.; Zhao, Y.; Mi, L.; Li, H.; Li, Y.; Zhang, J. Removal of gas-phase elemental mercury in flue gas by inorganic chemically promoted natural mineral sorbents. Ind. Eng. Chem. Res. 2012, 51, 3039-3047. [CrossRef]

10. Jampaiah, D.; Ippolito, S.J.; Sabri, Y.M.; Tardio, J.; Selvakannan, P.R.; Nafady, A.; Reddy, B.M.; Bhargava, S.K. Ceria-zirconia modified mnox catalysts for gaseous elemental mercury oxidation and adsorption. Catal. Sci. Technol. 2016, 6, 1792-1803. [CrossRef]

11. Reuß, M.; Ratke, L. Subcritically dried RF-aerogels catalysed by hydrochloric acid. J. Sol-Gel Sci. Technol. 2008, 47, 74-80. [CrossRef]

12. Zu, G.; Shen, J.; Zou, L.; Wang, F.; Wang, X.; Zhang, Y.; Yao, X. Nanocellulose-derived highly porous carbon aerogels for super capacitors. Carbon 2016, 99, 203-211. [CrossRef]

13. Liu, Z.; Li, X.; Lee, J.Y.; Bolin, T.B. Oxidation of elemental mercury vapor over $\gamma-\mathrm{Al}_{2} \mathrm{O}_{3}$ supported $\mathrm{CuCl}_{2}$ catalyst for mercury emissions control. Chem. Eng. J. 2015, 275, 1-7. [CrossRef]

14. Yang, J.; Zhao, Y.; Zhang, J.; Zheng, C. Removal of elemental mercury from flue gas by recyclable $\mathrm{CuCl}_{2}$ modified magnetospheres catalyst from fly ash. Part 1 . Catalyst characterization and performance evaluation. Fuel 2016, 164, 419-428. [CrossRef]

15. Zhou, Z.; Liu, X.; Hu, Y.; Liao, Z.; Cheng, S.; Xu, M. An efficient sorbent based on $\mathrm{CuCl}_{2}$ loaded $\mathrm{CeO}_{2}-\mathrm{ZrO}_{2}$ for elemental mercury removal from chlorine-free flue gas. Fuel 2018, 216, 356-363. [CrossRef] 
16. Sevilla, M.; Sanchís, C.; Valdés-Solís, T.; Morallón, E.; Fuertes, A.B. Direct synthesis of graphitic carbon nanostructures from saccharides and their use as electrocatalytic supports. Carbon 2008, 46, 931-939. [CrossRef]

17. Wu, D.; Fu, R.; Yu, Z. Organic and carbon aerogels from the NaOH-catalyzed polycondensation of resorcinol-furfural and supercritical drying in ethanol. J. Appl. Polym. Sci. 2005, 96, 1429-1435. [CrossRef]

18. Rasines, G.; Lavela, P.; Macı́as, C.; Zafra, M.C.; Tirado, J.L.; Parra, J.B.; Ania, C.O. N-doped monolithic carbon aerogel electrodes with optimized features for the electrosorption of ions. Carbon 2015, 83, 262-274. [CrossRef]

19. Yang, G.; Han, H.; Li, T.; Du, C. Synthesis of nitrogen-doped porous graphitic carbons using nano-CaCO $\mathrm{C}_{3}$ as template, graphitization catalyst and activating agent. Carbon 2012, 50, 3752-3765. [CrossRef]

20. Li, X.; Liu, Z.; Kim, J.; Lee, J.-Y. Heterogeneous catalytic reaction of elemental mercury vapor over cupric chloride for mercury emissions control. Appl. Catal. B Environ. 2013, 132-133, 401-407. [CrossRef]

21. Yang, J.; Zhao, Y.; Zhang, J.; Zheng, C. Removal of elemental mercury from flue gas by recyclable $\mathrm{CuCl}_{2}$ modified magnetospheres catalyst from fly ash: Part 2. Identification of involved reaction mechanism. Fuel 2016, 167, 366-374. [CrossRef]

22. Xu, H.; Qu, Z.; Zong, C.; Zong, C.; Huang, W.; Quan, F.; Yan, N. $\mathrm{MnO}_{x}$ /Graphene for the catalytic oxidation and adsorption of elemental mercury. Environ. Sci. Technol. 2015, 49, 6823-6830. [CrossRef] [PubMed]

23. Tao, S.; Li, C.; Fan, X.; Zeng, G.; Lu, P.; Zhang, X.; Wen, Q.; Zhao, W.; Luo, D.; Fan, C. Activated coke impregnated with cerium chloride used for elemental mercury removal from simulated flue gas. Chem. Eng. J. 2012, 210, 547-556. [CrossRef]

24. Tan, Z.; Sun, L.; Xiang, J.; Zeng, H.; Liu, Z.; Hu, S.; Qiu, J. Gas-phase elemental mercury removal by novel carbon-based sorbents. Carbon 2012, 50, 362-371. [CrossRef]

25. Yang, W.; Shan, Y.; Ding, S.; Han, X.; Liu, Y.; Pan, J. Gas-phase elemental mercury removal using ammonium chloride impregnated sargassum chars. Environ. Technol. 2018, 1, 1-14. [CrossRef] [PubMed]

26. Zhou, J.; Liu, Y.; Pan, J. Removal of elemental mercury from flue gas using wheat straw chars modified by $\mathrm{K}_{2} \mathrm{FeO}_{4}$ Reagent. Environ. Technol. 2017, 38, 3047-3054. [CrossRef] [PubMed]

27. Lee, S.J.; Seo, Y.C.; Jurng, J.; Tai, G.L. Removal of gas-phase elemental mercury by iodine- and chlorine-impregnated activated carbons. Atmos. Environ. 2004, 38, 4887-4893. [CrossRef]

28. Wu, J.; Yang, S.; Liu, Q.; He, P.; Tian, H.; Ren, J.; Guan, Z.; Hu, T.; Ni, B.; Zhang, C. Cu Nanoparticles inlaid mesoporous carbon aerogels as a high performance desulfurizer. Environ. Sci. Technol. 2016, 50, 5370-5378. [CrossRef]

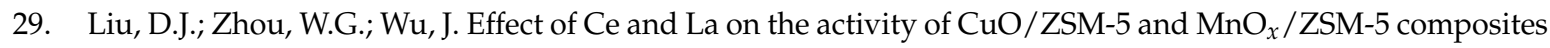
for elemental mercury removal at low temperature. Fuel 2017, 194, 115-122. [CrossRef]

30. Liu, D.J.; Lu, C.; Wu, J. Gaseous mercury capture by copper-activated nanoporous carbon nitride. Energy Fuels 2018, 32, 8287-8295. [CrossRef]

Sample Availability: Samples of the compounds are not available from the authors.

(C) 2018 by the authors. Licensee MDPI, Basel, Switzerland. This article is an open access article distributed under the terms and conditions of the Creative Commons Attribution (CC BY) license (http:/ / creativecommons.org/licenses/by/4.0/). 